\title{
Mechanism of Antifungal Triazoles and Related Drugs: Electron Transfer, Reactive Oxygen Species and Oxidative Stress
}

\author{
Peter Kovacic* and Marie-Caline Z Abadjian
}

Department of Chemistry and Biochemistry, San Diego State University, San Diego, California, USA

Received: 15 September, 2017; Accepted: 30 October, 2017; Published: 01 November, 2017

*Corresponding author: Peter Kovacic, Department of Chemistry and Biochemistry, San Diego State University, San Diego, California, USA. Tel: +1-619-594-5595; fax: +1-619-594-4634; E-mail: pkovacic@mail.sdsu.edu

\begin{abstract}
Aromatic triazoles are known to be effective antifungal agents. The generally accepted mode of action entails inhibition of ergosterol in the membrane. A hypothesis is presented herein based on Electron Transfer (ET), Reactive Oxygen Species (ROS) and Oxidative Stress (OS) which may be a unifying mechanism. Many substances in vivo are known to operate in a multifaceted manner. A prior article provides evidence for involvement of ET-ROS-OS for a variety of antifungal agents. In the present case, the active entity appears to be a highly conjugated imine. For drugs containing alcohol substituents, dehydration would provide the requisite conjugation. A few related aromatic nitrogen heterocycles are also addressed.

The unifying mechanism involving ET-ROS-OS, which has received substantial support, is applied to anti-fungul triazoles based on the ET imine-iminium portion, as part of a multifaceted scheme.
\end{abstract}

Keywords: Antifungal Agents; Triazoles; Electron Transfer; Reactive Oxygen Species; Oxidative Stress

\section{Abbreviations}

ET: Electron Transfer; ROS: Reactive Oxygen Species; OS: Oxidative Stress

\section{Introduction}

In 1990, a review presented a unifying mechanism for antifungal agents based on ET-ROS-OS [1]. Of particular interest involving the ET drugs are the iminium, e.g. triarylmethane dyes, such as gentian violet (Figure 1). The dyes are known to generate ROS via redox cycling. The one-electron reduction product interacts with oxygen to produce ROS which can damage DNA.

A prior integrating, mechanistic theme is as follows: A large portion of bioactive substances, including metabolites, utilize Electron Transfer (ET) processes which are believed to perform vital roles in physiological responses [2]. Groups, such as quinones (or phenolic precursors), metal complexes, aromatic nitro compounds (or reduced hydroxylamine and nitroso derivatives), and conjugated imine or iminium species, are key players in ET. Redox cycling from such species is depicted in
Scheme 1. Redox cycling in the presence of oxygen in vivo can lead to Oxidative Stress (OS) from the formation of Reactive Oxygen Species (ROS), such as hydrogen peroxide, hydroperoxides, alkyl peroxides, and diverse radicals (hydroxyl, alkoxyl, hydroperoxyl, and superoxide) shown in Scheme 2.

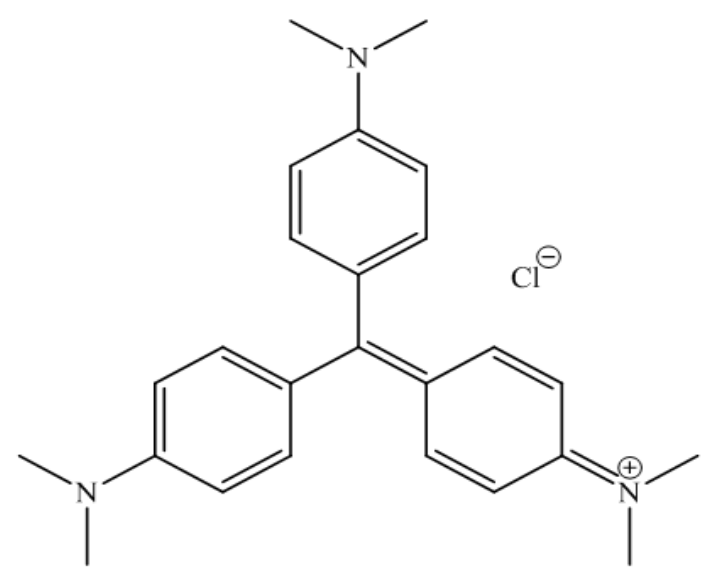

Figure 1: Gentian violet

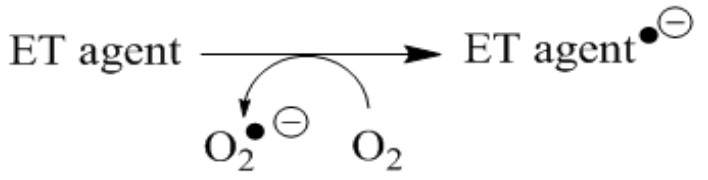

Scheme 1: Redox cycling with superoxide formation

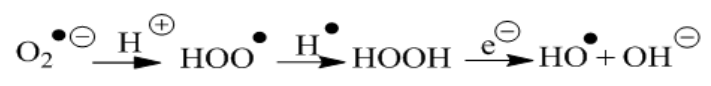

Scheme 2: Generation of reactive oxygen species 
In some instances, like respiration or neurochemistry, normal electrical effects are brought about by ET involvement. Bioactive substances with ET groups broadly show reduction potential ranges within the physiologically responsive spectrum (more positive than about $-0.5 \mathrm{~V}$ ). Consequently, the production of ROS from ET in vivo, at low concentration, can be favorable in cell signaling, but at high concentration it can be toxic. Relatively stable radical cations are generated from electron donors, such as phenols, $\mathrm{N}$-heterocycles or disulfides in proteins. The mechanisms of action of drugs and toxins (e.g., anti-infective agents [3], anticancer drugs [4], carcinogens [5], reproductive toxins [6], nephrotoxins [7], hepatotoxins [8], cardiovascular toxins [9], nerve toxins [10], mitochondrial toxins [8], abused drugs [11], pulmonary toxins [12], ototoxins [13] and various other categories [14] have increasingly been attributed to ET, ROS, and OS over the past decade.

\section{The Hypothesis}

The ET-ROS theoretical scheme has been receiving mounting acceptance through increasing experimental evidence. The evidence provides data on the involvement of the common ROS mentioned previously, e.g. lipid peroxidation, degradation products of oxidation, depletion of antioxidants (AOs), effect of exogenous AOs, and DNA oxidation and cleavage products, and electrochemical data, which supports the ET-ROS scheme. Frequent observations showing a myriad of ET substances present a diversity of activities (e.g. multiple-drug properties) and toxic effects, which is consistent with this comprehensive, unifying mechanism of action.

The triazole class, important antifungal agents, is usually considered to function by inhibition of ergosterol resulting in membrane insult. This article presents a unifying hypothesis based on ET-ROS-OS for mechanistic involvement in a multifaceted approach. Triazole is an aromatic heterocycle containing an imine group, one of the principal classes of ET agents. Extended conjugation is required for ET which is provided by benzenoid substituents. In some cases, conjugation arises via alcohol dehydration which generates a vinylogous system. The basic imine in the heterocycle readily undergoes protonation to an iminium which is generally more electron affinic in ET. The imine can also increase electron attraction by hydrogen bonding or $\mathrm{N}$-oxidation. Redox by iminium is depicted in Scheme 3 .

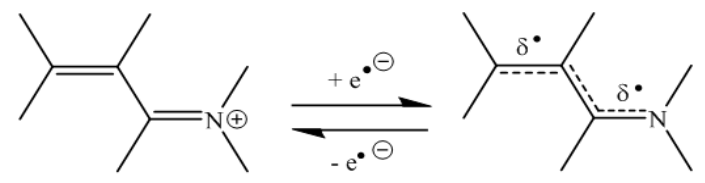

Scheme 3: ET by iminium

\section{Evaluation of the Hypothesis}

\section{Itraconazole}

This triazole antifungal agent is also used for meningitis and systemic infections, such as for candidiasis (Figure 2). Several studies demonstrate activity as an anticancer agent [15,16,17]. A review deals with the unifying theme of ET-ROS-OS for anticancer drugs, including conjugated imine [4]. The agent is closely related structurally to posaconazole.

The literature addresses mode of action as being the same as other members of the class, namely inhibition of ergosterol synthesis. It is distinct in inhibiting the hedgehog signaling pathway $[18,19]$. In relation to the ET-ROS-OS scheme, the aromatic triazole (Hückel's Rule, $4 n+2 \pi$ electrons, $n=1$ ) is in conjugation with the benzene substituent, thus providing stabilization of the generated radical anion (Figure 3).

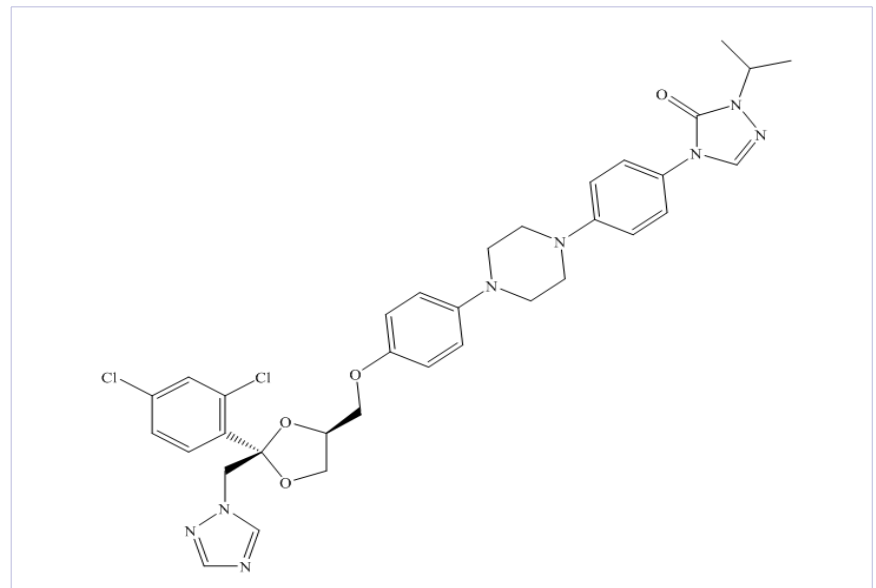

Figure 2: Itraconazole

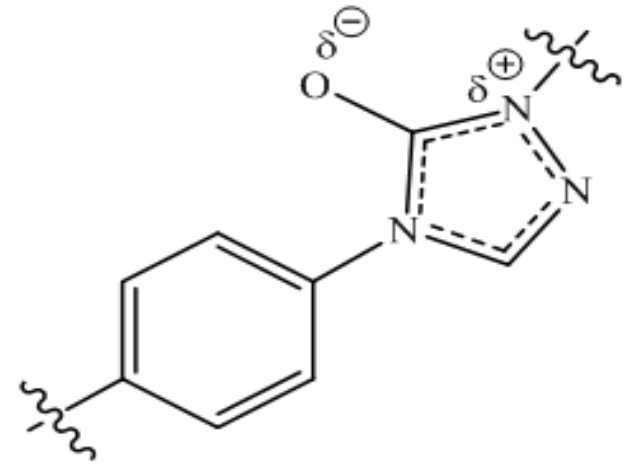

Figure 3: Conjugated aromatic triazole

Metabolism mainly entails hydroxylation of the triazole ring [20]. Studies of ocular toxicity in rabbits indicates safety except for high doses which caused retinal necrosis [21]. In one study, synthesized triazole fungicides were made and showed antifungal activity against Aspergillus niger and Aspergillus flavus [22]. The conjugation with the triazole is realized by the bromophenyl group (Figure 4).

Synthesized triazole-quinone/phenyl conjugates were tested for their antimicrobial activity and found to exhibit antifungal and antibacterial activity [23] (Figure 5). The quinolone portion attached to the triazole provides the requisite conjugation. 
<smiles>CC1(C)CC(=O)C2=C(C1)NC=C(C(=O)O)C2c1ccc(OCc2cn(-c3ccc(Br)cc3)nn2)cc1</smiles>

Figure 4: 1,2,3-Triazole-linked pentasubstituted 1,4-dihydropyridine<smiles>[Y]C1CC(=O)C2C(C1)Oc1ccc3ccc(OCc4cn(-c5ccnc6cc(Cl)ccc56)nn4)cc3c1C2[Y9]</smiles>

Figure 5: Triazole-quinone/phenyl conjugate

\section{Posaconazole}

This antifungal agent is quite similar in structure to itraconazole (Figure 6). It is also used to counter Candida species and is very effective against Chagas disease and lupus [24, 25].

The mechanism is reported to entail blockage of ergosterol synthesis and impairing enzymes, such as ATPase, lanosterol demethylase and ET enzymes. Interaction with the ET enzyme adds credence to ET action by the drug. Rationale for participation in the unifying ET-ROS-OS scheme is provided in the itraconazole section, involving conjugation of the aromatic triazole with the benzenoid group $\left(\mathrm{C}_{6} \mathrm{H}_{4}\right)$.

\section{Efinaconazole}

This drug, also called Jublia, is used to treat fungal infections, mainly of the nail (Figure 7). The drug inhibits ergosterol biosynthesis in the membrane, thereby adversely affecting fungal cell growth [26]. Evidence is presented in the prior sections pointing to involvement of conjugation by triazole substituents.

Although Jublia itself does not fit into the scheme, dehydration of the alcohol would yield a conjugated vinylogous triazole metabolite shown in Figure 8. The acid catalyst depicted in the pseudo-5-membered ring is derived from the protonated triazole (Figure 7). Hence this entity should be capable of participating in the unifying ET-ROS-OS mechanistic scheme.

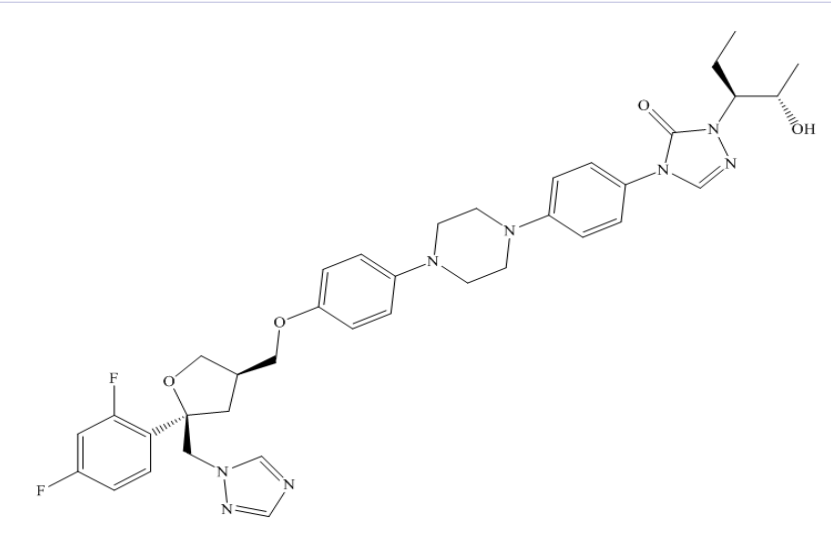

Figure 6: Posaconazole<smiles>C=C1CCN([C@@H](C)[C@](O)(Cn2cncn2)c2ccc(F)cc2F)CC1</smiles><smiles>C=C1CCN([C@@H](C)[C@](O)(Cn2cncn2)c2ccc(F)cc2F)CC1</smiles>

Figure 7: Efinaconazole (Jublia) (left); protonated Jublia (right)<smiles>C/C(=C/n1cncn1)c1ccc(F)cc1F</smiles>

Figure 8: Vinylogous triazole from Jublia

\section{Fluconazole}

This triazole, which bears close structural resemblance to Jublia, is marketed for treatment of fungal infections (Figure 9). It plays a role where other drugs have failed.

Although there are reports of various adverse effects, such as nausea, rash, fatigue, anorexia, headache and seizures, the drug appears to be relatively safe [27]. It is similar to other triazoles by inhibiting ergosterol synthesis in the membrane. In relation to 
the ET-ROS-OS mechanism, the drug can be compared with Jublia in potentially undergoing metabolism to the conjugated species illustrated in Figure 10. It is interesting that the same vinylog is formed from dehydration involving the other triazole ring.<smiles>OC(Cn1cncn1)(Cn1cncn1)c1ccc(F)cc1F</smiles>

Figure 9: Fluconazole<smiles>Fc1ccc(/C(=C/n2cncn2)Cn2cncn2)c(F)c1</smiles>

Figure 10: Vinylogous triazole from fluconazole

\section{Voriconazole}

This antifungal triazole agent belongs to the alcohol category (Figure 11). It is similar to amphotericin B and fluconazole in efficacy $[28,29]$. Side effects are similar to others of this class except for blurred vision or increased sensitivity to light. Metabolically, hydroxylation appears to be more important than $\mathrm{N}$-oxidation [30].

There are prior studies on phenazine and quinoxaline $\mathrm{N}$-oxides [31,32]. The imine- $\mathrm{N}$-oxide is related to iminium in exhibiting enhanced electron affinity. Protonation would increase cationic character. As for the other alcohols, dehydration would generate a conjugated vinylogous metabolite (Figure 12). A similar structure is derived from dehydration involving the other heterocycle.

\section{Isavuconazole}

Antifungal activity is also exhibited by this triazole (Figure 13). The potency was compared in vivo versus those of voriconazole and fluconazole [33]. Isavuconazole also belongs to the alcoholcontaining class. In vivo dehydration can conceivably generate the conjugated, vinylogous metabolite illustrated in Figure 14.
The compound should be capable of redox cycling in accord with the ET-ROS-OS mode of action. Alternatively, dehydration might occur to produce the vinylogous system incorporating the thiazole heterocycle.<smiles>C[C@@H](c1ncncc1F)[C@@](O)(Cn1cncn1)c1ccc(F)cc1F</smiles>

Figure 11: Voriconazole<smiles>CS/C(=C/c1ccc(F)cc1F)n1cncn1</smiles>

Figure 12: Vinylogous triazole from Voriconazole

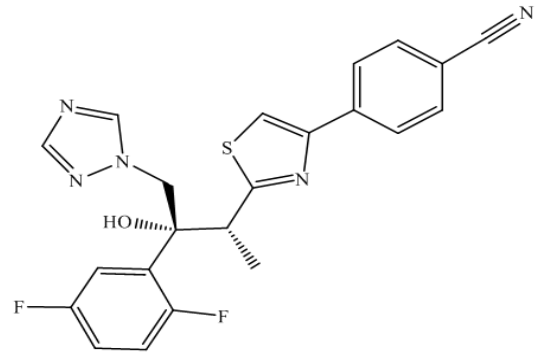

Figure 13: Isavuconazole<smiles>CC(C)n1cncn1</smiles>

Figure 14: Vinylogous triazole from isavuconazole 


\section{Pramiconazole}

This triazole antifungal agent has been less investigated in comparison to its closely related structural analogs, namely itraconazole and posaconazole (Figure 15). A significant portion of the prior discussion for the similar two drugs should also be applicable in this case. Close inspection of the structure suggests that the drug may function as a precursor of the triazole alcohol class. The acetal segment could readily undergo hydrolysis to a keto group capable of reduction to an alcohol. Subsequent dehydration, would yield the vinylogous, conjugated system which would be capable of ET.

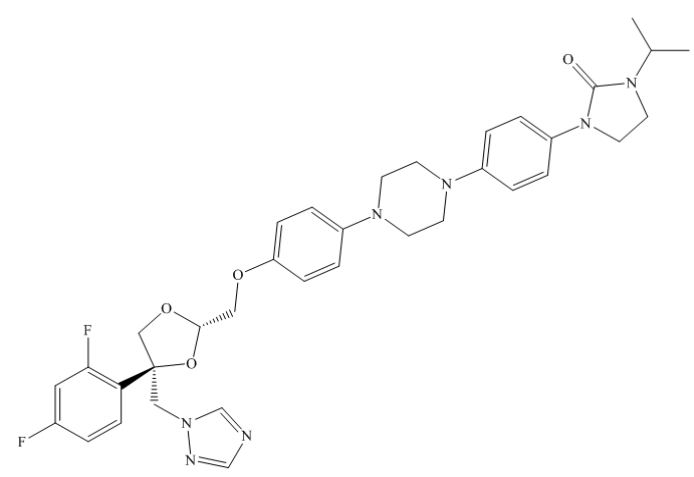

Figure 15: Pramiconazole

\section{Propiconazole}

A study was made of modulation of glutathione-related antioxidant defense system of fish treated by the triazole fungicide propiconazole (Figure 16) [34]. OS in rainbow trout was measured, as well as oxidative damage. It interferes with esgosterol Mechanistic aspects are discussed under pramiconazole. In rats, hepatotoxicity was displayed by propiconazole, triadimefon, and myclobutanil [35]. A prior review applies the ET-ROS-OS scheme to hepato toxins [8].

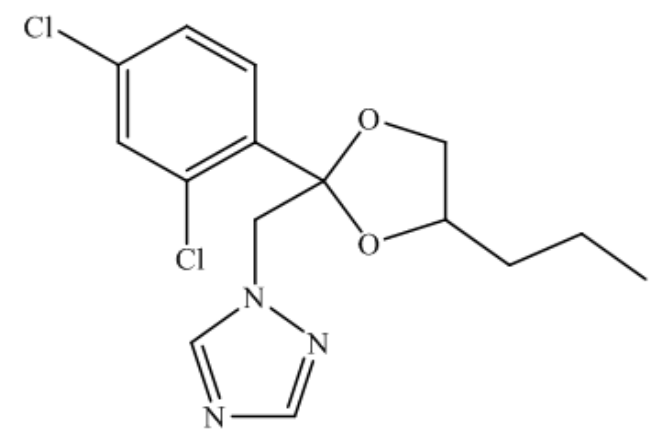

Figure 16: Propiconazole

\section{Suvorexant}

This drug, not an antifungal agent, belongs to the triazole class, and is structurally related to itraconazole and posaconazole in possessing a benzenoid groups in conjugation with the heterocycle (Figure 17). Suvorexant, mainly used for treatment of insomnia, is an orexin receptor antagonist [36]. The amidesubstituent on the benzene ring should aid in delocalization of the radicals in the ET process. The triazole in this drug is related to the 1,2-diimine class which is known to possess ET properties as a simple functionality [37].<smiles>Cc1ccc(-n2nccn2)c(C(=O)N2CCN(c3nc4cc(Cl)ccc4o3)CC[C@H]2C)c1</smiles>

Figure 17: Suvorexant

\section{Miconazole}

This antifungal agent is quite akin to the triazole class except for imidazole in place of triazole (Figure 18). In addition, there is similarity in mode of action entailing inhibition of ergosterol synthesis in the membrane. The drug may function as a precursor of the alcohol class via ether cleavage followed by dehydration to the conjugated vinylogous system. Ether scission can occur by hydrolysis or oxidative dealkylation.

\section{Clotrimazole}

This antifungal medication is on the WHO list of important drugs. It also functions by inhibiting ergosterol biosynthesis in the membrane (Figure 19).

Although there are similarities to the triazole class, there is difference in the presence of the imidazole heterocycle. Another difference is the obvious absence of extended conjugation. However, there is precedent for radical delocalization during ET. Computational studies were performed on ET by the iminium metabolite of phencyclidine (PCP) [38].

Although vinyl delocalization is not possible, the process can occur as depicted in Figure 20 via a pseudo-3-membered ring. A similar situation can be visualized for delocalization after electron uptake by PCP iminium as illustrated in Figure 21.

Similar delocalization is conceivable for the protonated (iminium) form of imidazole.

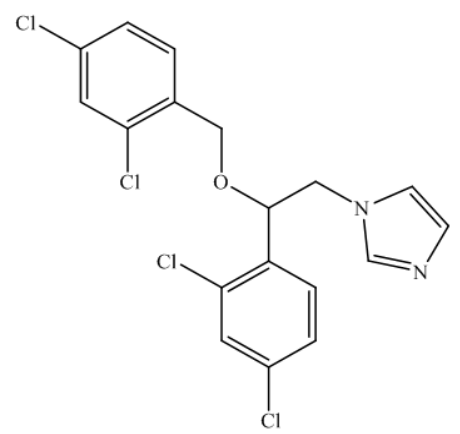

Figure 18: Miconazole 


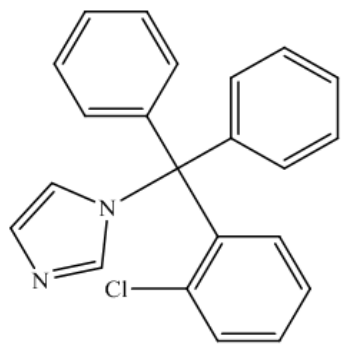

Figure 19: Clotrimazole

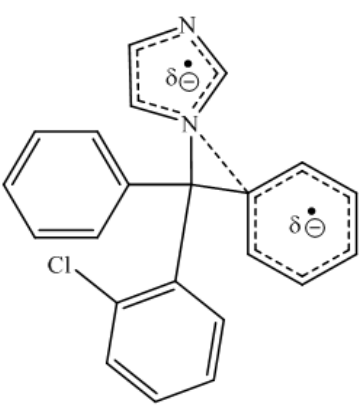

Figure 20: Delocalization from electron uptake by clotrimazole

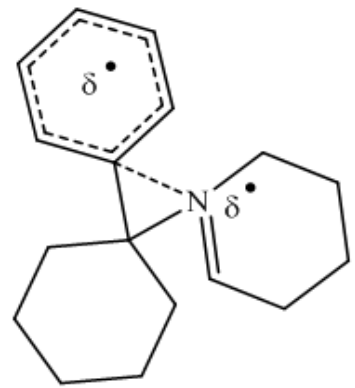

Figure 21: Delocalization from electron uptake by PCP iminium

\section{Echinocandins}

Echinocandins comprise a recent class of antifungal drugs, including anidulafungin (ALF) and caspofungin (CPF) in addition to micafungin. The natural antifungal agent micafungin inhibits an essential polysaccharide in fungal cell walls [39, 40, 41]. A result is osmotic instability and lysis of the cell (Figure 22).

The heteroaromatic oxazole portion incorporates the heterocycle in conjugation with two benzenoid rings which should make possible redox cycling in accord with the ET-ROS-OS theme (Figure 23). The heterocycle contains a conjugated imine which fits into the ET category.

There is additional significant literature. The most common adverse effects are nausea and enhanced levels of transamine [42]. Rats developed liver tumors at high dose. Safety appears to be good in humans. The drug generates cell stress involving interference with the redox state that is counteracted by AOs
[43]. GSH levels are reduced. This behavior is in accord with participation of ET-ROS-OS.

All three are quite safe. ALF and CPF belong to the phenolic group of drugs which may function via the quinone metabolites in accord with ET-ROS-OS [44]. ALF also incorporates a phenolic ether that has the potential for dealkylation to a quinone via a phenol conjugated with a bisphenyl. In animals, CPF can exhibit embryotoxic properties which may involve ROS [45, 46].

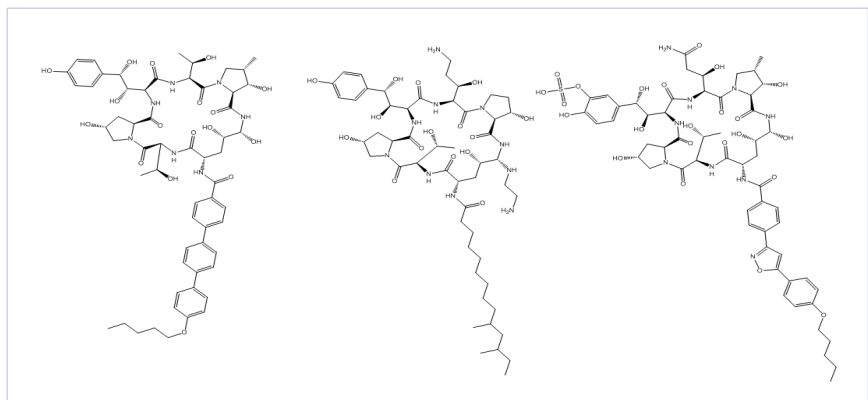

Figure 22: Anidulafungin (top left) and Caspofungin (top right), and micafungin (below)

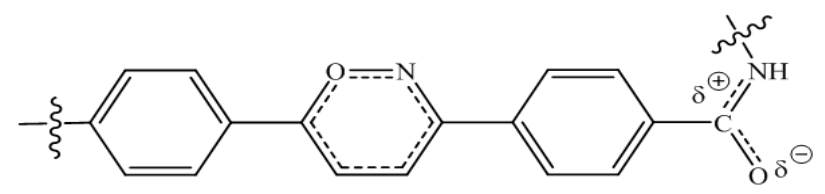

Figure 23: Conjugated oxazole portion

\section{Alprazolam}

The drug, also called Xanax, is a member of the triazole family used mainly in treatment of anxiety (Figure 24) [47]. It is related to some antifungal agents in being in conjugation with a benzenzoid. It is interesting in being incorporated with a benzodiazepine unit which also fits into the ET-ROS-OS scheme [48]. Xanax became a blockbuster drug in the U.S. and alprazolam is the most prescribed. The potential for misuse is controversial.

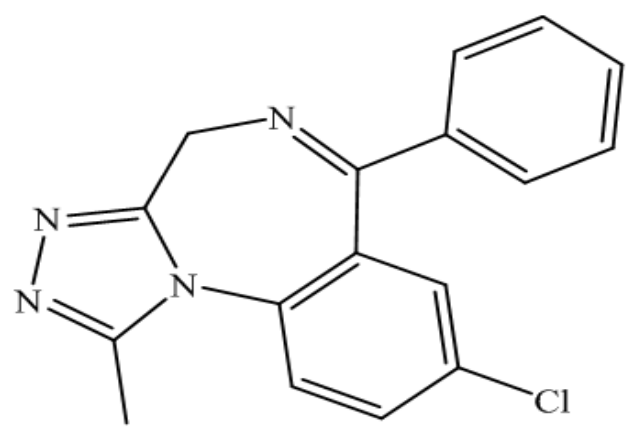

Figure 24: Alprazolam 


\section{Evaluation of hypothesis}

There are various methods by which the hypothesis can be tested involving the parent compound or the active metabolite. Reduction potentials, based on polarography or cyclic voltammetry, provide information concerning ability to accomplish ET in vivo. The conjugated alkenes from alcohol dehydration could be synthesized for examination. Analytical methods can be used to detect the presence of ROS which are postulated to arise from ET. Addition of AOs would decrease ROS.

\section{Other Support Material}

A Quantitative Structure Activity Relationships (QSAR) study was performed on toxicity by triazole fungicides [49] Findings demonstrate that electron exchange may occur between the drugs and the target. The data adds credibility to the ET portion of the ET-ROS-OS unifying theme. In vitro experiments revealed hyperinduction of $\mathrm{H} 2 \mathrm{O} 2$ production by the fungicide prothioconazole (Figure 25) [50]. This important finding concerning ROS formation by the fungicide prothioconazole supports the ET-ROS-OS unifying theme.

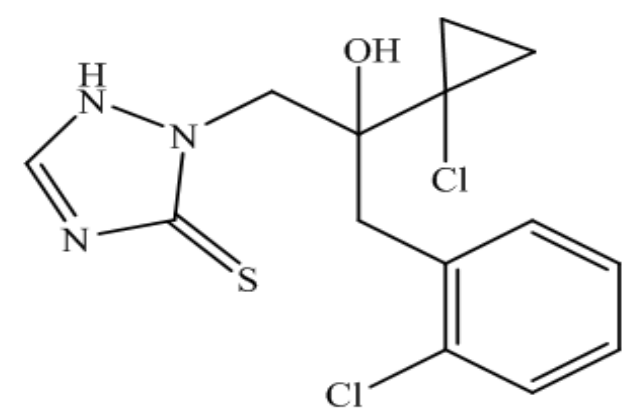

Figure 25: Prothioconazole

In another study, the physiological and biochemical responses in different tissues of fish from exposure to fungicide propiconazole [FC2] indicated that PCZ-induced the stressful conditions (Figure 16) [51]. The stress is in in accord with OS arising from generation of ROS in the unifying mechanism.

Other support in this journal which is relevant to the unifying mode of action is available, for example, anticancer agents [52] neurotoxic 3,3'-iminodipropionitrile [53], nicotine [54], cocaine [55], and 4-oxo-2-nonenal versus 4-hydroxy-2-nonenal [56].

The unifying mechanism involving ET-ROS-OS, which has received substantial support, is applied to anti-fungul triazoles based on the ET imine-iminium portion, as part of a multifaceted scheme.

\section{Summary}

The ET imine-iminium segment of antifungal triazoles is often part of a conjugated system. In some cases, conjugation may be achieved via metabolism, such as alcohol dehydration. Suggestions for future work relative to the unifying mechanism are presented.

\section{Acknowledgement}

Editorial assistance by Thelma Chavez is acknowledged.

\section{References}

1. Kovacic P, Kiser PF, Feinberg BA. Are reduction potentials of antifungal agents relevant to activity? Pharmaceut Res. 1990;7(3):283-288.

2. Kovacic P, Somanathan R. Mechanism of conjugated imine and iminium species, including marine alkaloids: electron transfer, reactive oxygen species, therapeutics and toxicity. Curr Bioact Compds. 2010;6(1):46-59.

3. Kovacic P, Becvar LE. Mode of action of anti-infective agents: focus on oxidative stress and electron transfer. Curr Pharm Des. 2000;6(2):143167

4. Kovacic P, Osuna JA. Mechanisms of anti-cancer agents: emphasis on oxidative stress and electron transfer. Curr Pharmaceut Des. 2000;6(3):277-309.

5. Kovacic P, Jacintho JD. Mechanism of carcinogenesis. Focus on oxidative stress and electron transfer. Curr Med Chem. 2001;8(7):773-796.

6. Kovacic P, Jacintho JD. Reproductive toxins. Pervasive theme of oxidative stress and electron transfer. Curr Med Chem. 2001;8(7):863-892.

7. Kovacic P, Sacman A, Wu-Weis M. Nephrotoxins: Widespread role of oxidative stress and electron transfer. Curr Med Chem. 2002;9(8):823847

8. Poli G, Cheeseman KH, Dianzani MU, Slater TF. Free Radicals in the Pathogenesis of Liver Injury. Pergamon: New York 1989;1-365.

9. Kovacic P, Thurn LA. Cardiovascular toxicity from the perspective of oxidative stress, electron transfer, and prevention by antioxidants. Curr Vasc Pharmacol. 2005;3(2):107-117.

10. Kovacic P, Pozos RS, Somanathan R, Shangari R, O’Brien PJ. Mechanism of mitochondrial uncouplers, inhibitors, and toxins: Focus on electron transfer, free radicals, and structure-activity relationships. Curr Med Chem. 2005;12(22):2601-2623.

11. Kovacic P, Cooksy AL. Unifying mechanism for toxicity and addiction of abused drugs: electron transfer and reactive oxygen species. Med Hypotheses. 2005;64(2):357-366

12. Kovacic P, Somanathan R. Pulmonary toxicity and environmental contamination: radicals, electron transfer, and protection by antioxidants. Rev Environ Contam Toxicol. 2009;201:41-69. doi: 10.1007/978-14419-0032-6_2

13. Kovacic P, Somanathan R. Ototoxicity and noise trauma: Electron transfer, reactive oxygen species, cell signaling, electrical effects, and protection by antioxidants: Practical medical aspects. Med Hypotheses. 2008;70(5):914-923.

14. Halliwell B, Gutteridge JMC. Free Radicals in Biology and Medicine. New York: Oxford University Press; 1999. p. 1-897.

15. Aftab BT, Dobromilskaya I, Liu JO, Rudin CM. Intraconazole inhibits angiogenesis and tumor growth in non-small cell lung cancer. Cancer Res. 2011;71(21):6764-6772. doi: 10.1158/0008-5472.CAN-11-0691

16. Antonarakis ES, Heath EI, Smith DC, Rathkopf D, Blackford AL, Danila DC, et al. Repurposing itraconazole as a treatment for advanced 
prostate cancer: a noncomparative randomized phase II trial in men with metastatic castration-resistant prostate cancer. Oncologist. 2013;18(2):163-173. doi: 10.1634/theoncologist.2012-314

17. Rudin CM, Brahmer JR, Juergens RA, Hann CL, Ettinger DS, Sebree R, et al. Phase 2 study of pemetrexed and itraconazole as second-line therapy for metastatic nonsquamous non-small-cell lung cancer. J Thorac Oncol. 2013;8(5):619-623. doi: 10.1097/JT0.0b013e31828c3950

18. Kim J, Tang JY, Gong R, Kim J, Lee JJ, Clemons KV, et al. Itraconazole, a commonly used antifungal that inhibits hedgehog pathway activity and cancer growth. Cancer Cell. 2010;17(4):388-399. doi: 10.1016/j. ccr.2010.02.027

19. Kim J, Aftab BT, Tang JY, Kim D, Lee AH, Rezaee M, et al. Itraconazole and arsenic trioxide inhibit hedgehog pathway activation and tumor growth associated with acquired resistance to smoothened antagonists. Cancer Cell. 2013 Jan 14;23(1):23-34. doi: 10.1016/j. ccr.2012.11.017

20. Yi Y, Yoon HJ, Kim BO, Shim M, Kim SO, Hwang SJ, et al. A mixed polymeric micellar formulation of itraconazole: Characteristics, toxicity and pharmacokinetics. J Control Release. 2007;117(1):59-67.

21. Cone LA, Himelman RB, Hirschberg JN, Hutcheson JW. Itraconazolerelated amaurosis and vomiting due to digoxin toxicity. West J Med. 1996;165(5):322

22. Singh H, Sindhu J, Khurana JM, Sharma C, Aneja KR. A facile eco-friendly one-pot five-component synthesis of novel 1,2,3-triazole-linked pentasubstituted 1.4-dihydropyridines and their biological and photophysical studies. Australian J Chem. 2013;66(9):1088-1096.

23. Singh H, Nand B, Sindhu J, Khurana JM, Sharma C, Aneja KR. Efficient one pot synthesis of xanthene-triazole- quinoline/phenyl conjugates and evaluation of their antimicrobial activity. J Braz Chem Soc. 2014;25(7):1178-1193

24. Li X, Brown N, Chau AS, López-Ribot JL, Ruesga MT, Quindos G, et al. Changes in susceptibility to posaconazole in clinical isolates of Candida albicans. J Antimicrob Chemother. 2004;53(1):74-80.

25. Pinazo MJ, Espinosa G, Gállego M, López-Chejade PL, Urbina JA, Gascón, J. Successful treatment with posaconazole of a patient with chronic Chagas disease and systemic lupus erythematosus. Am J Trop Med Hyg. 2010;82(4):583-587. doi: 10.4269/ajtmh.2010.09-0620

26. Yoshiyuki T, Maria N, Toshiyuki S, Atsushi I, Yumi K, Fumie I, et al. Mechanism of action of efinaconazole, a novel triazole antifungal agent. Antimicrob Agents Chemother. 2013;57(5):2405-2409. doi: 10.1128/AAC.02063-12

27. Rossi S. Australian Medicines Handbook. Adelaide; 2006.

28. Patterson T, Boucher H, Herbrecht R, Denning D, Lortholary, O, Ribaud, P, et al. Strategy of following voriconazole versus amphotericin B therapy with other licensed antifungal therapy for primary treatment of invasive aspergillosis: impact of other therapies on outcome. Clin Infect Dis. 2005;41(10):1448-1452

29. Kullberg BJ, Sobel JD, Ruhnke M, Pappas PG, Viscoli C, Rex JH, et al Voriconazole versus a regimen of amphotericin B followed by fluconazole for candidaemia in non-neutropenic patients: a randomized non-inferiority trial. Lancet. 2005;366(9495):1435-1442.

30. Geist MJ, Egerer G, Burhenne J, Riedel KD, Weiss J, Mikus G. Steadystate pharmacokinetics and metabolism of voriconazole in patients. J Antimicrob Chemother. 2013;68(11):2592-2599. doi: 10.1093/jac/ dkt229

31. Ryan MD, Scamehorn RG, Kovacic P. Charge transfer in the mechanism of drug action involving quinoxaline di-N-oxides. J Pharm Sci. 1985;74(4):492-495.

32. Crawford PW, Scamehorn RG, Hollstein U, Ryan MD, Kovacic P. Cyclic voltammetry of phenazines and quinoxalines including mono- and di$\mathrm{N}$-oxides. Relation to structure and antimicrobial activity. Chem Biol Interact. 1986;60(1):67-84.

33. Guinea J, Peláez T, Recio S, Marta TN, Bouza E. In vitro antifungal activities of Isavuconazole (BAL4815), voriconazole and fluconazole against 1,007 isolates of zygomycete, Candida, Aspergillus, Fusarium, and Scedosporium species. Antimicrob Agents Chemother. 2008;52(4):1396-1400.

34. Li ZH, Zlabek V, Grabic R, Li P, Randak T. Modulation of glutathionerelated antioxidant defense system of fish chonically treated by the fungicide propiconazole. Comp Biochem Physiol C Toxicol Pharmacol. 2010;152(3):392-398. doi: 10.1016/j.cbpc.2010.06.006

35. Hester SD, Wolf DC, Nesnow S, Thai SF. Transcription profiles in liver from rats treated with tumorigenic and non-tumorigenic triazole conazole fungicides: propiconazole, triadimefon, and myclobutanil. Toxicol Pathol. 2006;34(7):879-894.

36. Baxter CA, Cleator E, Brands KMJ, Edwards JS, Reamer RA, Sheen FJ, et al. The First Large-Scale Synthesis of MK-4305: A Dual Orexin Receptor Antagonist for the Treatment of Sleep Disorder. Org Proc Res Develop. 2011;15(2):367-375

37. Niufar NN, Haycock FL, Wesemann JL, MacStay JA, Heasley VL, Kovacic P. Reduction potentials of conjugated aliphatic ketones, oximes and imines: Correlation with structure and bioactivity. Rev Chem Soc Mex. 2002;46(4):307-312.

38. Kirshner KN, Van Dyke C, Kovacic P, Bowen JP. Computational studies on electron transfer by the iminium metabolite of phencyclidine (PCP). Theo Chem. 2000;498(1-3):167-179.

39. Kofla, G, Ruhnke M. Pharmacology and metabolism of anidulafungin, caspofungin and micafungin in the treatment of invasive candidosis: review of the literature. Eur J Med Res. 2011;16(4):159-166.

40. Pappas PG, Rotstein CM, Betts RF, Nucci M, Talwar D, De Waele JJ, et al. Micafungin versus caspofungin for treatment of Candidemia and other forms of invasive Candidiasis. Clin Infect Dis. 2007;45(7):883893.

41. Pettengell K, Mynhardt J, Kluyts T, Lau W, Baraldi E, Botes ME, et al. Successful treatment of oesophageal Candidiasis by micafungin: a novel systemic antifungal agent. Aliment Pharmacol Ther. 2004;20(4):475481.

42. Valerio M, Muñoz P, Bouza E. Liver toxicity of micafungin. Is the drug safe? Enferm Infecc Microbiol Clin. 2011;29 Suppl 2:29-32. doi: 10.1016/S0213-005X(11)70006-4

43. Maras B, Angiolella L, Mignogna G, Vavala E, Macone A, Colone M, et al. Glutathione metabolism in Candida albicans resistant strains to fluconazole and micafungin. PLoS One. 2014;9(6):e98387. doi: 10.1371/ journal.pone.0098387

44. Kovacic P, Abadjian MC, Somanathan R. Natural monophenols as therapeutics, antioxidants and toxins; electron transfer, radicals and oxidative stress. The Natural Products Journal. 2015;5(3).

45. Jimmy B, Jose J, Saravu K, Shastry BA. Caspofungin: a novel broad- 
spectrum antifungal agent. Pharmacologyonline. 2007;2:73-84

46. Kovacic P, Somanathan R. Mechanism of teratogenesis: electron transfer, reactive oxygen species and antioxidants. Birth Defects Res C Embryo Today. 2006;78(4):308-325.

47. Mandrioli R, Mercolini L, Raggi MA. Benzodiazepine metabolism: an analytical perspective. Curr Drug Metab. 2008;9(8):827-844.

48. Kovacic P, Ott N, Cooksy AL. Benzodiazepines: electron affinity, receptors, and cell signaling - a multifaceted approach. J Recept Signal Transduct Res. 2013;33(6):338-343. doi: 10.3109/10799893.2013.830129

49. Ding F, Guo J, Song W, Hu W, Li Z. Comparative quantitative structureactivity relationship (QSAR) study on acute toxicity of triazole fungicides to zebrafish. Chem Ecol. 2011;27(4):359-368.

50. Audenaert K, Callewaert E, Hofte M, De Saeger S, Haesaert G. Hydrogen peroxide induced by the fungicide prothioconazole triggers deoxynivalenol (DON) production by Fusarium graminearum. BMC Microbiol. 2010;10:112. doi: 10.1186/1471-2180-10-112

51. Li ZH, Zlabek V, Velisek J, Grabic R, Machova J, Kolarova J, et al. Multiple biomarkers responses in juvenile rainbow trout, Oncorhynchus mykiss, after acute exposure to a fungicide propiconazole. Environ Toxicol. 2013;28(3):119-126. doi: 10.1002/tox.20701
52. Kovacic P. Unifying mechanism for anticancer agents involving electron transfer and oxidative stress: clinical applications. Med Hypotheses. 2007;69(3):510-516.

53. Kovacic P. Mechanism of neurotoxic 3,3'-iminodipropionitrile: relation to unsaturated nitriles, cocaine, and reactive oxygen species. Med Hypotheses. 2005;66:210-216.

54. Kovacic P, Cooksy A. Iminium metabolite mechanism for nicotine toxicity and addiction: oxidative stress and electron transfer. Med Hypotheses. 2005;64(1):104-111.

55. Kovacic P. Role of oxidative metabolites of cocaine in toxicity and addiction: oxidative stress and electron transfer. Med Hypotheses. 2005;64(2):350-356.

56. Kovacic P. Novel electrochemical approach to enhanced toxicity of 4-oxo-2-nonenal vs. 4-hydroxy-2-nonenal (role of imine): oxidative stress and therapeutic modalities. Med Hypotheses. 2006;67(1):151156 